\title{
Value Added as an Indicator of Effectiveness of Strategizing High-Tech Sector in Raw Material Region
}

\author{
Anna V. Moskvina 1[ORCID 0000-0002-6845-0716], \\ Irina V. Filimonenko 1[ORCID 0000-0003-1237-5478], \\ Tatiana P. Likhacheva 1[ORCID 0000-0001-6814-0438], \\ Varvara V. Borodkina 1[ORCID 0000-0002-6708-6588], \\ Svetlana V. Mikhailova ${ }^{1 *[O R C I D}$ 0000-0002-6472-3756]
}

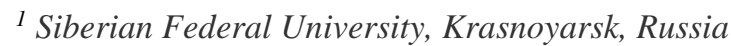
svguts@mail.ru

\begin{abstract}
The article examines the issues of structural technological inclusions characteristic of the raw material region and the way out of them due to various options for strategizing economic activity. The emphasis is made on the competitiveness of products of high-tech business and its ability to accumulate added value, which changes the intersectoral structural proportions in the economic system of the region. A sequence of research tasks was determined, including the formation of a portfolio of high-tech products in accordance with the demand for them in various product markets with a subsequent assessment of the effects of strategizing and the growth of added value in the high-tech sector and manufacturing industries in the region. The assessment of the competitiveness of high-tech products was made based on the systematization of information on the possibilities of entering the domestic and world markets by taking into account supply and demand in these markets. The selection criteria and the conditions for dividing into groups in terms of priorities were determined. This allows high-tech products to be grouped for promotion in various markets. Priority positioning schemes for high-tech products make it possible to designate their specific portfolios for promotion in the domestic market, including importsubstituting products, and in world commodity markets. Forecasting value added within the designated portfolios of high-tech products accumulates the effects of possible transformational changes in the structure of the region's economic system. The value-added strategy changes the technological structure of the manufacturing industry in the region, ensuring its high-quality growth and focus on innovative development.
\end{abstract}

Keywords: added value, competitiveness, high-tech sector, product positioning, strategizing, transformation of the economic system

\section{INTRODUCTION}

In the concepts of structural development of the economy, cyclical fluctuations play an important role, during which the properties of self-organization of the economy are manifested. Cyclical fluctuations as the mechanisms of adaptation of the socioeconomic system to external changes are the basis for the formation of structural proportions of the economy. In structural dynamics, the most important is the formation of an economic and technological paradigm based on intellectual resources, which are structure-determining changes in the economy [1].

Thus, in the process of structural convergence, technological dynamics determines not only the processes of changing technological paradigms and the creation of a basis for new technologies, but also the inclusion of medium-tech sectors with a powerful development potential.

The definition of structural technological inclusion refers to the involvement of medium-tech 
sectors of the regional economy in the industrialization process and the modernization of low-tech industries (Figure 1). As a result, various strategies for the development of technological sectors (different in terms of technology) of the economy are formed, which constitute the strategic vector of technological development of the region's economy as a whole [2].

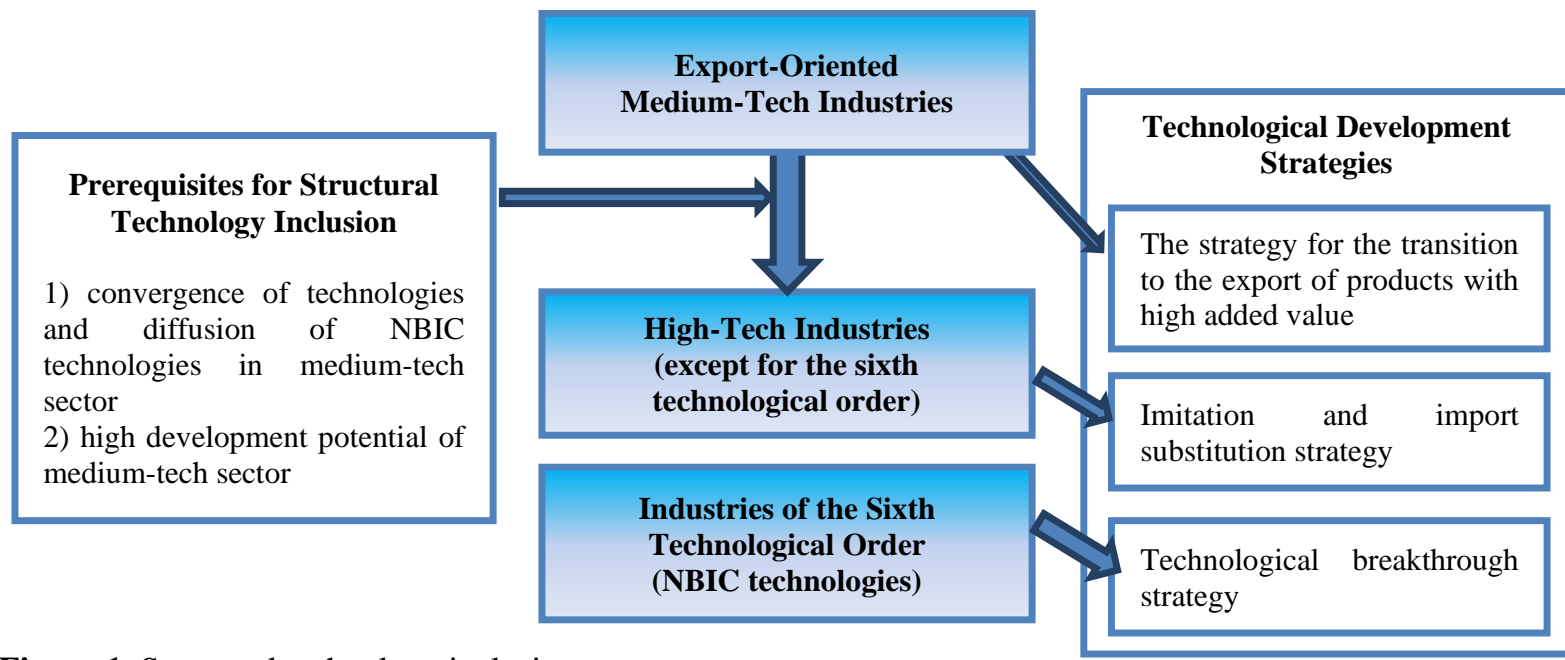

Figure 1. Structural technology inclusion

Source: Compiled by the authors

Technological inclusion is implemented on the basis of enterprises of the high-tech sector, through the production of high-tech products that provide high added value and demand for the formation of new product markets at the national and international levels (Figure 2).

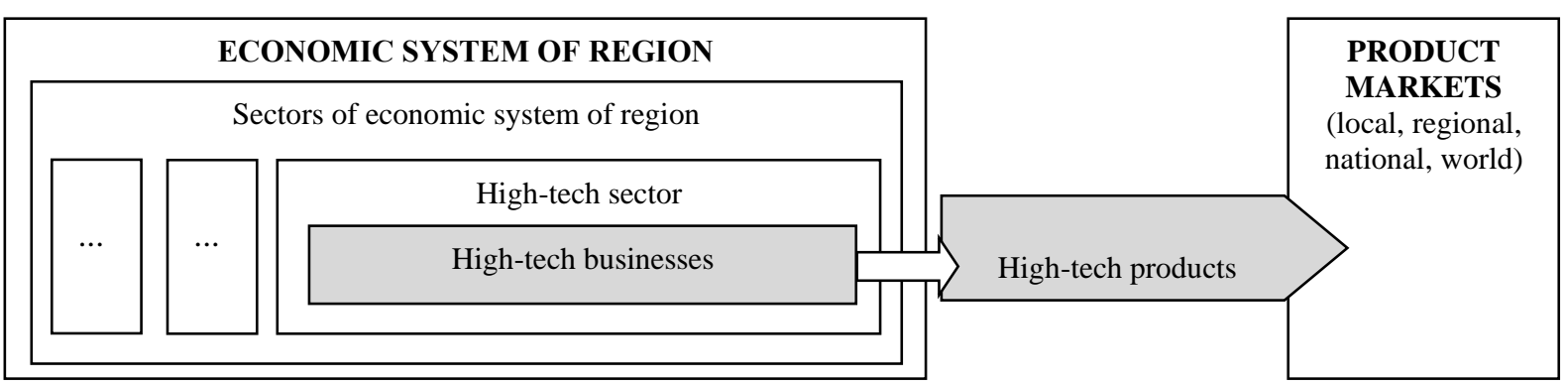

Figure 2. Influence of high-tech sectors on formation of economic system of region and product markets Source: Compiled by the authors

In general, the development of a high-tech sector in the economy of a resource-based region makes it possible to ensure the formation of sustainable competitive advantages due to the ability of regional companies to independently generate value chains based on the expansion of the production of hightech products $[3,4]$.

The transformational possibilities of the economic system of the region under the influence of the development of markets for high-tech products are determined by changes, first of all, in the very structure of high-tech businesses operating in the region. At the same time, the emergence of new industries affects the change in the structure of the region's industry and the transformation of its economic system as a whole (Figure 3).
It is advisable to evaluate the change in the sectoral structure of the region, taking into account the promotion of high-tech products to various product markets, and using the value added indicator [5, 6].

Strategic factors of increasing the competitiveness of economic entities were focused on in the works of M. Porter, who introduced the concept of a value chain into scientific circulation and for the first time developed an integral methodology for its analysis [7]. According to M. Porter, the relative level of analysis of added value creation is the activity of a company or business unit in a particular industry. From the point of view of the author of the concept, the analysis of the industry is not advisable, since inevitable generalizations blur the picture of competitive 
advantages, depleting the basis of analysis. Moreover, the value chains of competing companies within the same industry have significant differences. Therefore, product manufacturing technologies will be a determining factor in efficiency and competitiveness. Technological development refers to various technologies used both in the activity to create added value and directly in the engineering and technological equipment of the production process itself.

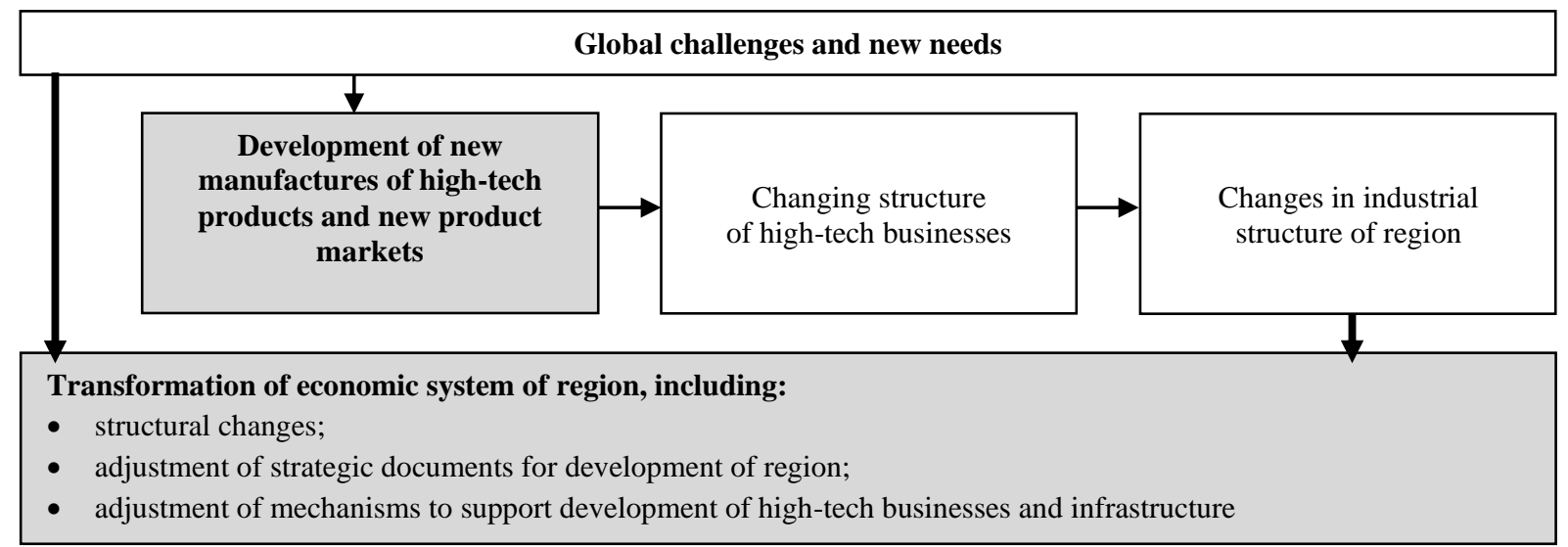

Figure 3. Transformation of economic system of region under influence of development of high-tech product markets

Source: Compiled by the authors

This is especially clearly reflected in the elemental structure of value added, which includes wages fund, depreciation and profit. In addition, value added characterizes the productivity of economic entities at different levels of management and can serve as a generalizing indicator of the effectiveness of strategizing processes.

Over the past five years, an increase in the added

32.5 Manufacture of medical instruments and equipment

27 Manufacture of electrical equipment

28 Manufacture of machinery and equipment not included in other categories

26 Manufacture of computers, electronic and optical products

21 Manufacture of medicines and materials used for medical purposes

30 Manufacture of other vehicles and equipment

29 Manufacture of motor vehicles, trailers and semitrailers

20 Manufacture of chemicals and chemical products

33 Repair and installation of machinery and equipment

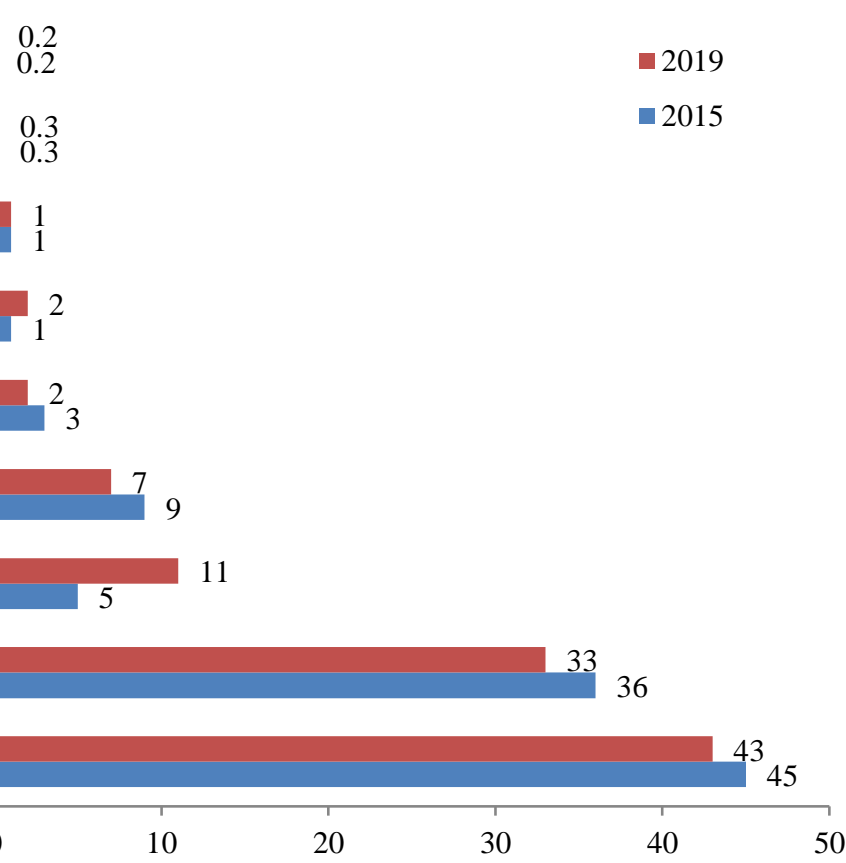

value of the manufacturing sector has been observed in the Krasnoyarsk Territory: the growth rate in 20152019 amounted to $83 \%$. There is also an increase in the share of this sector in the GVA of the Krasnoyarsk Territory: from $44 \%$ in 2015 to $57 \%$ by 2019.

The high-tech sector in the structure of the manufacturing industry in the Krasnoyarsk Territory is small (Figure 4).

Figure 4. Structure of high-tech sector of the Krasnoyarsk Territory in 2015 and 2019, \% Source: Compiled by the authors

Source: Compiled by the authors 
For the period 2015-2019, there is an increase in its added value (74\%). In the structure of the hightech sector, the largest shares (over 30\%) are OKVED (All-Russian Classifier of Economic Activities) 33 "Repair and installation of machinery and equipment" (43\%), OKVED 20 "Production of chemicals and chemical products" (33\%). Shares of more than $5 \%$ are for such OKVEDs as 29 "Production of motor vehicles, trailers and semitrailers" $(11 \%)$ and 30 "Manufacture of other vehicles and equipment" (7\%). The remaining sectors account for less than 3\% (OKVEDs 21, 26, $28,27,32.5)$.

The imbalance of added value in foreign economic activity within the high-tech sector indicates insufficient technological effectiveness and, as a consequence, competitiveness, which predetermines the need to search for growth reserves by entering new promising markets and strategizing these opportunities.

\section{MATERIALS AND METHODS}

The strategic development of a raw material region has its own characteristics associated with the need to activate the processes of innovative and technological renewal of its industries. In our opinion, the need of the regional economic system for such development is due to the presence of prerequisites for the development of high-tech businesses from the point of view of the areas of activity existing in the territory and the demand for corresponding products on the national and world markets [8].

In this regard, the authors proceed from the need to select and form a portfolio of high-tech business based on assessing the competitiveness of products produced or planned for production in the region for national and world commodity markets with its subsequent impact on the transformation of structural changes (Figure 5).

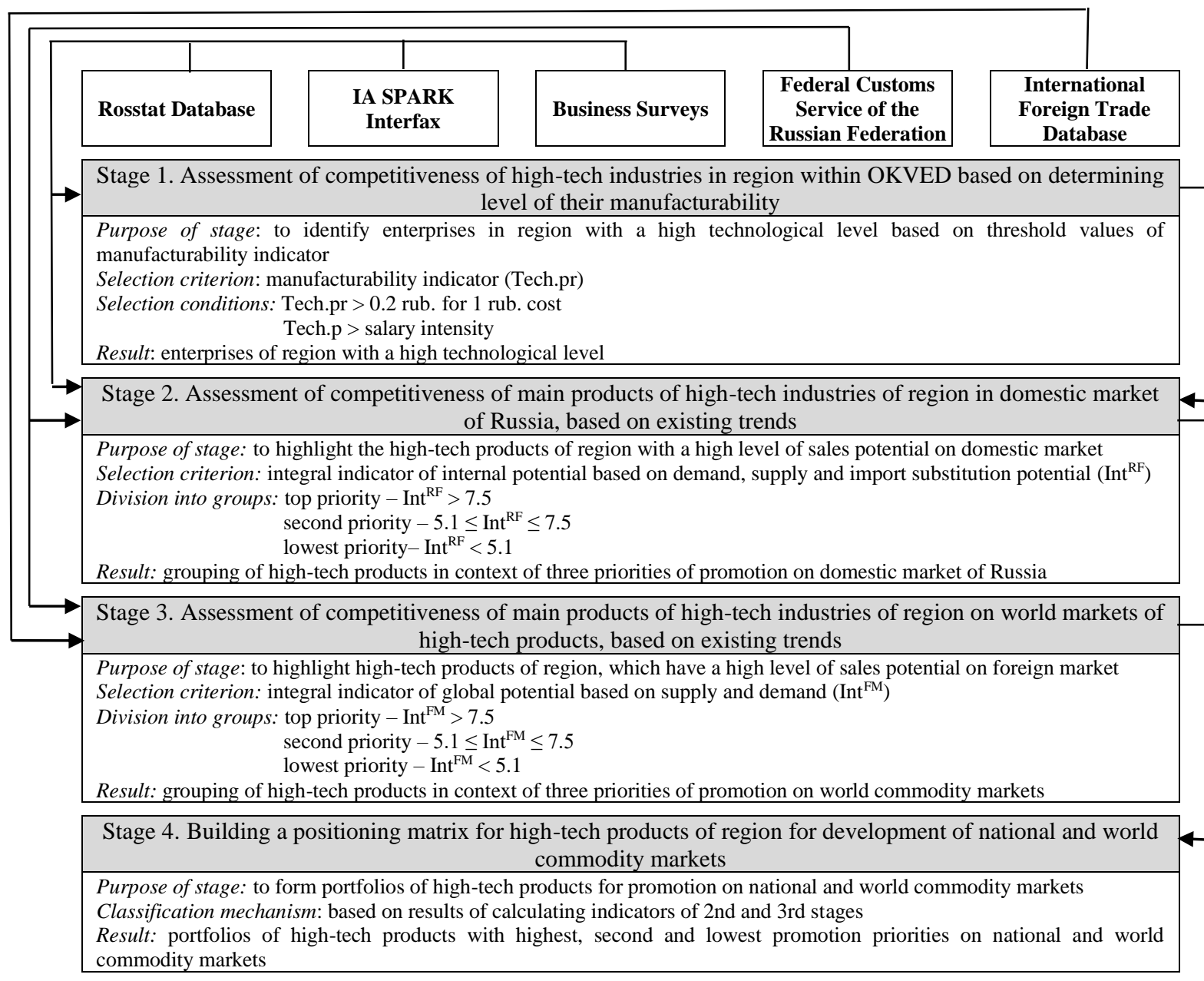

Figure 5. Sequence of market positioning of high-tech businesses in economic system of raw materials region Source: Compiled by the authors 
Evaluation of sectoral structure of the region, taking into account the promotion of high-tech products to the national and world commodity markets, is carried out on the basis of effects of transformational abilities of the economic system, depending on competitiveness of the business. Its main stages are presented in Table 1.

Table 1. Evaluation of effects of transformational abilities of economic system of a resource-based region depending on competitiveness of high-tech businesses

\begin{tabular}{l|r} 
Stage & Stage content \\
\hline
\end{tabular}

Information Support:

SPARK (System of Professional Analysis of Markets and Companies) Interfax, Rosstat, Customs statistics of foreign trade, surveys of enterprises

Stage 1 Forecasting performance indicators of high-tech industries taking into account new data

Stage 2 Evaluation of performance indicator of high-tech businesses in region:

\begin{tabular}{|c|c|c|}
\hline Indicator & Calculation procedure & Norm \\
\hline 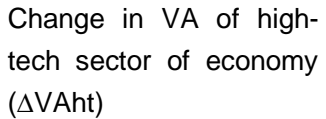 & $\begin{array}{l}\triangle V A h t=V \text { Vht }_{1}-\text { VAht }_{0} \\
\text { where: VAht } \\
\text { is projected revenue of } H T \text { sector, VAht }\end{array}$ & More than 0 \\
\hline
\end{tabular}

If the indicator corresponds to the norm, then the increase in the performance of the high-tech sector of the region is confirmed

Stage 3 Evaluation of structural changes in regional economic system:

\begin{tabular}{|c|c|c|}
\hline Indicator & Calculation procedure & Evaluation \\
\hline $\begin{array}{l}\text { Change in the share of } \\
\text { the high-tech sector in } \\
\text { GVA ( } \Delta \text { SHTgrp) }\end{array}$ & $\begin{array}{l}\Delta \text { SHTgrp }=\text { SHTgrp }_{1}-\text { SHTgrp }_{0} \\
\text { where: SHTgrp }{ }_{1} \text { is projected share of HT sector of economy in } \\
\text { GVA, SHTgrp }_{0} \text { is basic share of HT sector of economy in GRP }\end{array}$ & More than 0 \\
\hline $\begin{array}{l}\text { Change in the share of } \\
\text { the high-tech sector in } \\
\text { the manufacturing } \\
\text { industry }(\Delta S H T m n f)\end{array}$ & $\begin{array}{l}\triangle \mathrm{SHTmnf}=\mathrm{SHTmnf}_{1}-\mathrm{SHTmnf}_{0} \\
\text { where: } \mathrm{SHTmnf}_{1} \text { is projected share of } \mathrm{HT} \text { sector of economy in } \\
\text { manufacturing industry, SHTmnf }{ }_{0} \text { is basic share of } \mathrm{HT} \text { sector of } \\
\text { economy in manufacturing industry }\end{array}$ & More than 0 \\
\hline $\begin{array}{l}\text { Change in the share of } \\
\text { manufacturing in GVA } \\
\text { (SMNFgrp) }\end{array}$ & $\begin{array}{l}\triangle \text { SMNFgrp } \text { SMNFgrp }_{1}-\text { SMNFgrp }_{0} \\
\text { where: } \text { SMNFgrp }_{1} \text { is projected share of manufacturing in GVA, } \\
\text { SMNFgrp }_{0} \text { is basic share of manufacturing in GVA }\end{array}$ & More than 0 \\
\hline
\end{tabular}

If all indicators correspond to the norm, then the positive dynamics of structural changes in the regional economic system is confirmed

Source: Compiled by the authors

The efficiency of high-tech businesses in the region is based on an assessment of changes in the added value of the high-tech sector of the economy ( $\triangle$ VAht).

Structural shifts in the regional economic system are assessed by three indicators: a change in the share of the high-tech sector of the economy in the GVA ( $\Delta$ SHTgrp), changes in the share of the hightech sector of the economy in the manufacturing industry $(\triangle \mathrm{SHTmnf})$ and the change in the share of manufacturing in the GVA (SMNFgrp) of the region.

\section{RESULTS}

Priority types of economic activities in the region were identified based on the results of a survey of regional representatives of high-tech business (Table 2).

Assessment of their competitiveness on the domestic and world markets, using the proposed methods, made it possible to form three portfolios of competitive high-tech businesses in the Krasnoyarsk Territory [9]:

- a portfolio of competitive high-tech businesses for the domestic market (taking into account the potential of import substitution);

- a portfolio of competitive import-substituting high-tech products for the domestic market;

- a portfolio of competitive high-tech businesses for the global market. 
Table 2. Priority types of economic activities of high and medium high technological level, implemented in the Krasnoyarsk Territory

\begin{tabular}{|c|c|}
\hline OKVED & Name \\
\hline \multicolumn{2}{|r|}{ High-tech industries } \\
\hline 26 & Manufacture of computers, electronic and optical products \\
\hline 30.3 & Manufacture of aircraft, including spacecraft, and related equipment \\
\hline \multicolumn{2}{|r|}{ Mid-level high-tech industries } \\
\hline 27 & Manufacture of electrical equipment \\
\hline 28 & Manufacture of machinery and equipment not included in other groupings \\
\hline 29 & Manufacture of motor vehicles, trailers and semi-trailers \\
\hline 30 excluding 30.3 & $\begin{array}{l}\text { Manufacture of other vehicles and equipment (excluding construction of ships and boats; manufacture of } \\
\text { aircraft, including spacecraft, and related equipment) }\end{array}$ \\
\hline 32.5 & Manufacture of medical instruments and equipment \\
\hline 33 & Repair and installation of machinery and equipment \\
\hline
\end{tabular}

Source: Compiled by the authors

Evaluation of the efficiency of high-tech businesses in the region was carried out on the basis of changes in the added value of companies in the high-tech sector of the economy of the Krasnoyarsk Territory ( $\triangle$ VAht).
Table 3 presents the forecast of the added value of the high-tech sector of the economy of the Krasnoyarsk Territory before and after the implementation of the strategies: $\triangle \mathrm{VAht}-$ an increase of $90 \%$.

Table 3. Forecast of gross value added in high-tech sector of economy of the Krasnoyarsk Territory before and after development of high-tech industries

\begin{tabular}{|l|c|c|c|c|c|}
\hline \multicolumn{1}{|c|}{ Indicators, billion rubles } & $\mathbf{2 0 1 9}$ & $\mathbf{2 0 2 1}$ & $\mathbf{2 0 2 5}$ & $\mathbf{2 0 3 0}$ & Increase, \% \\
\hline GVA base option & 90.1 & 94.6 & 112.2 & 134.3 & 49 \\
\hline Increase & 0.0 & 24.0 & 30.3 & 36.6 & \\
\hline GVA new option & 90.1 & 118.5 & 142.5 & 171.0 & 90 \\
\hline
\end{tabular}

Source: Compiled by the authors

The assessment of structural changes in the regional economic system was carried out according to: a change in the share of the high-tech sector of the economy in the GVA ( $\Delta$ SHTgrp), a change in the share of the high-tech sector of the economy in the manufacturing industry ( $\Delta$ SHTmnf) and a change in the share of manufacturing industries in the GVA (SMNFgrp) of the region.

Table 4 shows the forecast of these indicators:

- $\Delta$ SHTgrp - from $3.8 \%$ to $4.9 \%$;
- $\Delta$ SHTmnf - from $6.76 \%$ to $8.6 \%$;

- Rgrp - from $56.8 \%$ to $57.9 \%$.

By 2030, according to the results of calculations, the structure of the selected OKVED relative to the manufacturing sector will change in the direction of growth in volumes, value added and shares: the total share of OKVEDs 26, 27, 28 and 30 in the manufacturing sector will increase from $3 \%$ to $5.2 \%$ (Figure 6).

Table 4. Forecast of changes in share of high-tech sector and manufacturing industry and their shares in regional GVA

\begin{tabular}{|l|c|c|c|c|}
\hline \multicolumn{1}{|c|}{ Indicators, \% } & $\mathbf{2 0 1 9}$ & $\mathbf{2 0 2 5}$ & $\mathbf{2 0 3 0}$ & Increase, \% \\
\hline Share of high-tech sector of economy in GVA (base option) & 3.84 & 3.84 & 3.84 & 0.0 \\
\hline Share of high-tech sector of economy in GVA (new option) & 3.84 & 4.87 & 4.89 & 1.0 \\
\hline Share of high-tech sector in manufacturing industry (base option) & 6.76 & 6.76 & 6.76 & 0.0 \\
\hline Share of high-tech sector in manufacturing (new option) & 6.76 & 8.58 & 8.60 & 1.8 \\
\hline Share of manufacturing in GVA (base option) & 56.8 & 56.8 & 56.8 & 0.0 \\
\hline Share of manufacturing in GVA (new option) & 56.8 & 57.8 & 57.8 & 1.0 \\
\hline
\end{tabular}

Source: Compiled by the authors 
30 Manufacture of other vehicles and equipment

28 Manufacture of machinery and equipment not included in other groupings

27 Manufacture of electrical equipment

26 Manufacture of computers, electronic and optical products

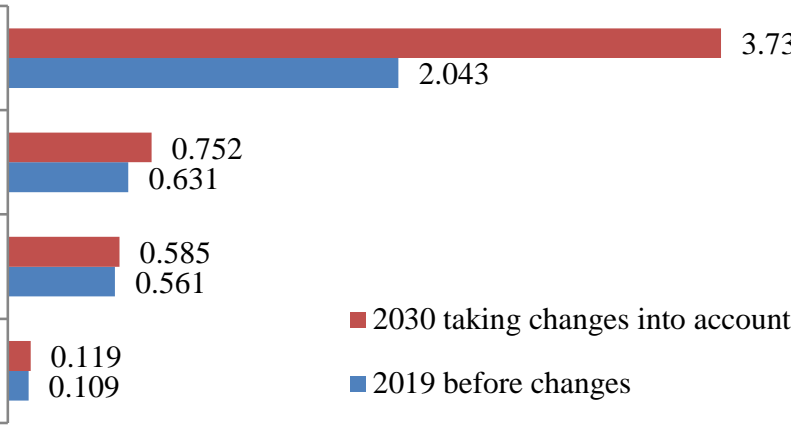

Figure 6. Shares of OKVED before and after changes in value added in manufacturing sector of the Krasnoyarsk Territory, \%

Source: Compiled by the authors

According to the results of calculations, the annual growth of the manufacturing sector of the Krasnoyarsk Territory due to the expansion of existing industries and the creation of new ones will be about $1.8 \%$ (Figure 7 ).

The results of assessing the effects of the transformational abilities of the economic system of

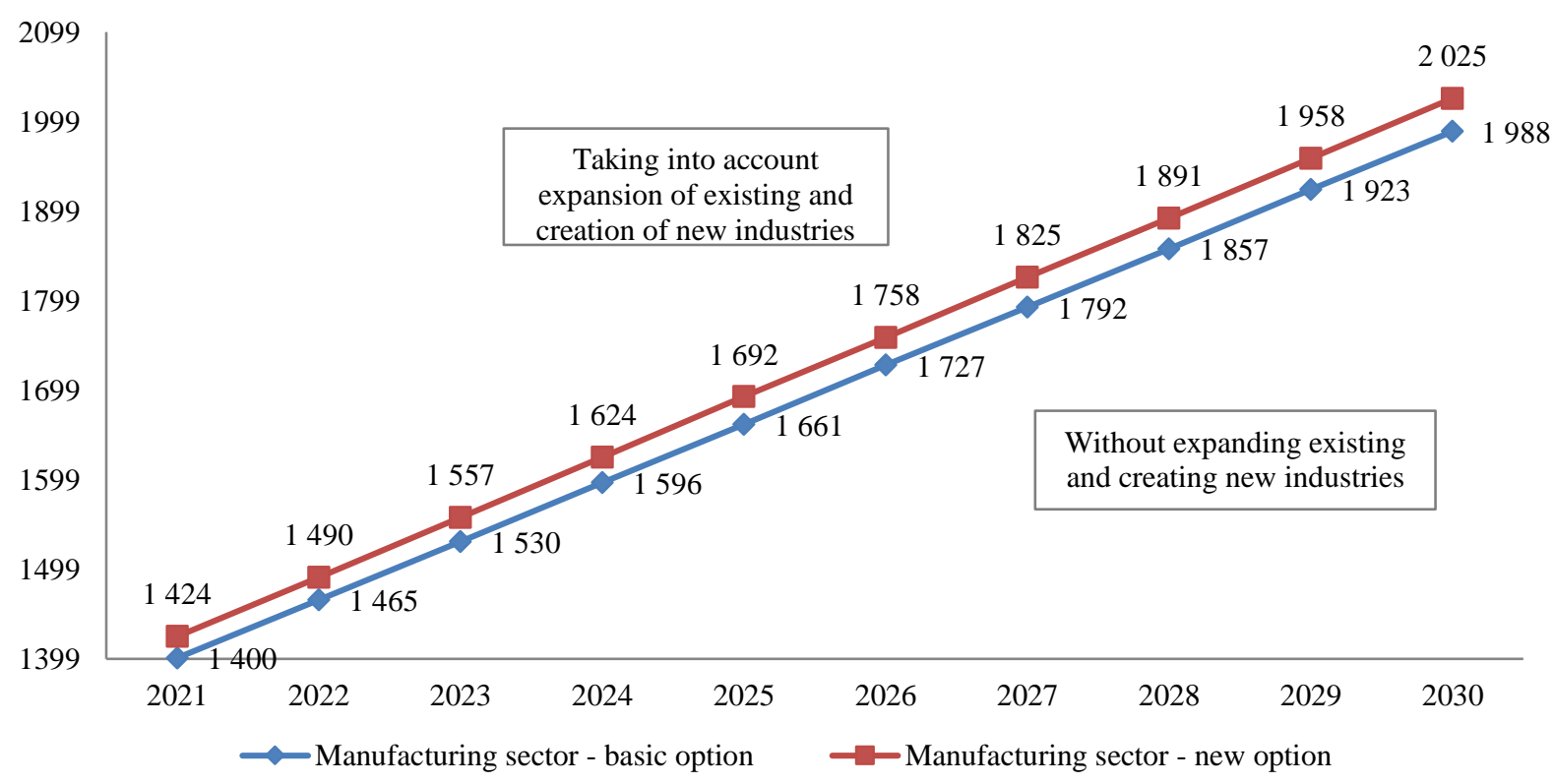

Figure 7. Dynamics of value added in manufacturing sector of the Krasnoyarsk Territory, billion rubles Source: Compiled by the authors

The forecasting of the value added of the surveyed enterprises according to OKVEDs 26, 27, 28 and 30 was carried out in the context of three basic strategies: expansion of sales of products in the domestic market (including for new and innovative products), expansion of sales of importsubstituting products and expansion of sales of products for export $[10,11]$.

According to the forecast, the added value of the studied OKVEDs 26, 27, 28 and 30 due to the the Krasnoyarsk Territory, depending on the competitiveness of high-tech businesses, and based on the growth of industrial production in accordance with the Strategy of socio-economic development of the Krasnoyarsk Territory until 2030 are presented below. Its scenario provides a $49 \%$ increase in gross value added.
.73

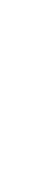

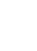




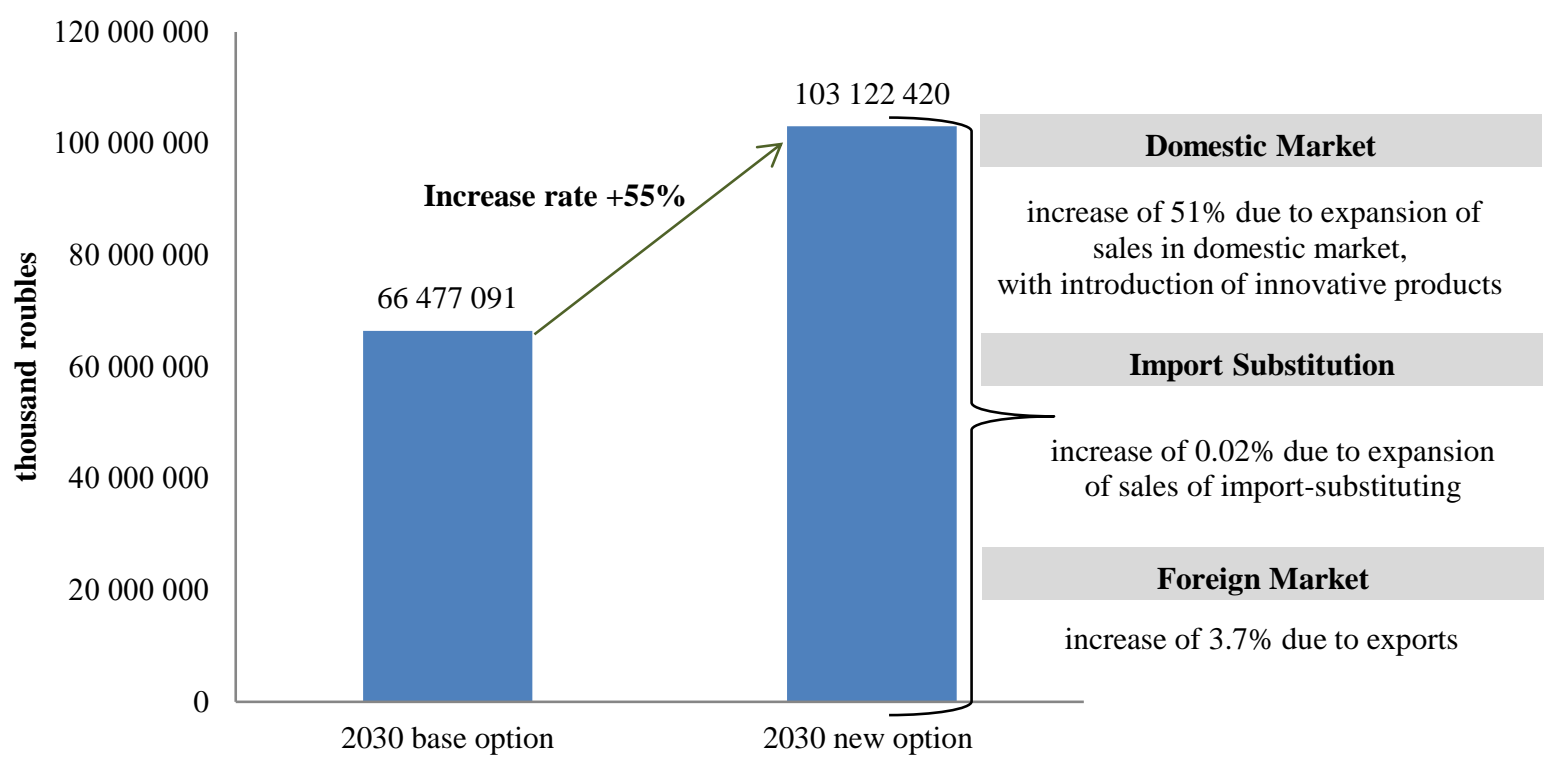

Figure 8. Value added of OKVEDs 26, 27, 28 and 30 for basic and new options for 2030, thousand rubles Source: Compiled by the authors

\section{DISCUSSION}

Testing the results shows the possibilities of forming directions for improving the mechanisms of management of scientific, technological and innovative development, increasing the efficiency of management and the sustainability of the socioeconomic development of the region.

The scientific and practical significance of the results provides the possibility of using the proposed tools by the subjects of management of the Krasnoyarsk Territory and other regions to make informed decisions on the development of industry and its branches in the direction of increasing their science intensity and manufacturability, opening up opportunities for entering promising export commodity markets.

\section{CONCLUSION}

The presented results allow us to highlight:

- methods for selecting priority types of hightech products based on the parameters of market positioning;

- a matrix model of structural needs of the regional economic system and types of hightech product markets;

- methods for assessing effects of the transformational abilities of the economic system of the region, depending on the competitiveness of high-tech products.
The obtained methodical materials can serve as tools for:

- carrying out the identification of product markets in order to determine the possibilities of optimizing structural elements of the economic system and improving mechanisms of their support;

- determining the structural needs of the economic system of a raw material region in high-tech products with the aim of transforming the economy in the direction of science intensity and manufacturability, and of forming a regional order;

- building a process for assessing the potential and choosing promising commodity markets for a raw material region, followed by adjusting the roadmap to increase the science intensity and manufacturability of the economic system.

\section{AUTHORS' CONTRIBUTIONS}

The authors made an equal contribution to the study: collection and analysis of material; definition of goals and objectives, research methods; formulation and scientific substantiation of conclusions, registration of key research results in the form of an article.

\section{ACKNOWLEDGMENTS}

The study was carried out within the framework 
of the Project "Research of Potential of New Materials Technologies, Production Technologies for New Types of High-tech Products and Mechanisms of Cooperation of Regional Manufacturers for Implementation of Priority Investment Projects and Strategic Repositioning on World Commodity Markets" (application code No. 2021020107139) with the support of the Krasnoyarsk Regional Science Foundation.

\section{REFERENCES}

[1] V. Mironov, L. Konovalova, "Structural changes and economic growth in the world economy and Russia", Russian Journal of Economics, 2019, vol. 5(1), pp. 1-26. DOI: 10.32609/j.ruje.5.35233

[2] S. Li, X. Zhang, H. Xu, S. Fang, E. Garces. T. Daim, "Measuring strategic technological strength: Patent Portfolio Model", Technological Forecasting and Social Change, 2020. vol. 157, p. 120119. DOI: 10.1016/j.techfore.2020.120119

[3] Y.A. Doroshenko, I.O. Malykhina, I.V. Somina, "Problems and prospects of scaling of hightech-business as an innovative investment driver of economic systems development", Espacios, 2018, vol. 39(47), p. 23.

[4] Yu.A. Doroshenko, M.S. Starikova, I.V. Somina, I.O. Malykhina, "Increasing the efficiency of high-tech companies based on interactions with the entities of the innovative environment", Economy of Region, 2019, vol. 15(4), pp. 1279-1293. (In Russ.). DOI: $10.17059 / 2019-4-24$

[5] I.A. Maslova, "Infrastructure concept of value formation and distribution of value added by groups of economic entities", [Infrastrukturnaya kontsentsiya obrazovaniya stoimosti i raspredeleniya dobavlennoy stoimosti po gruppam ekonomicheskikh sub"yektov], Finance and Credit, 2006, vol. 3(207), p. 46-54. (In Russ.).

[6] A.J. Saffer, "Value Added Theory", The International Encyclopedia of Strategic Communication, 2018.2 DOI: 10.1002/9781119010722.iesc0197

[7] Michael E. Porter, "Competitive advantage. Creating and sustaining Superior Performance", New York, The Free Press, 1985, 557 p.

[8] N.V. Akindinova, A.G. Nazarova, A.A. Chepel, "Macro-sectors in the Russian Economy: Structural Aspects and Responses to the External Conditions Changes", Journal of the New Economic Association, 2018, vol. 3(39), pp. 128-137. (In Russ.). DOI: 10.31737/22212264-2018-39-3-6

[9] A.N. Rusina, O.V. Karpycheva, I.V. Filimonenko, "Identifying high demand occupations and areas of training on the regional labor market", Creative Economy, 2017, vol. 11(11), pp. 1145-1156. (In Russ.). DOI: 10.18334/ce.11.11.38565

[10] A.N. Spartak, A.E. Likhachev, "Russia's export potential on the world market for innovations", Russian Foreign Economic Journal, 2017, vol. 10. pp. 3-22. (In Russ.).

[11] M. Javaid, A. Haleem, "Critical components of industry 5.0 towards a successful adoption in the field of manufacturing", Journal of Industrial Integration and Management, 2020, vol. 5(3), pp. 327-348. DOI: $10.1142 / \mathrm{S} 2424862220500141$ 